\title{
Silver hydrogel urinary catheters: Evaluation of safety and efficacy in single patient with chronic spinal cord injury
}

\author{
Irene M. Estores, MD; ${ }^{*}$ Deborah Olsen, RN, MPH; ${ }^{2}$ Orlando Gómez-Marin, MSc, $\mathbf{P h D}^{\mathbf{3}}$ \\ ${ }^{1}$ Spinal Cord Injury Service, James A. Haley Veterans' Hospital, Tampa, FL; ${ }^{2}$ Radiation Oncology and ${ }^{3}$ Clinical \\ Epidemiology and Public Health, University of Miami, Miami, FL
}

\begin{abstract}
Urinary tract infections (UTIs) are a large health burden for patients with spinal cord injury (SCI) who have neurogenic bladder dysfunction, especially those patients using indwelling catheters. One method that has shown promise in recent years is the use of a silver hydrogel catheter (SHC). This article describes the outcome of a subject who was part of a prospective, randomized, double-blind study and assigned to use an SHC for 6 months. Using the indwelling SHC effectively prevented this subject from developing a symptomatic UTI. He did not display any symptoms suggestive of silver toxicity or increased serum levels of silver with chronic use of the device. Although no general conclusions can be drawn from this single-subject observation, the results suggest that SHC use has a positive effect. Use of this catheter for persons with neurogenic bladder dysfunction after SCI should be explored further with a study design that optimizes subject recruitment.
\end{abstract}

Key words: bacteriuria, bladder management, catheter, indwelling catheter, neurogenic bladder dysfunction, rehabilitation, silver hydrogel catheter, silver toxicity, spinal cord injury, urinary tract infection.

\section{INTRODUCTION}

Urinary tract infections (UTIs) place a large health burden on patients with spinal cord injury (SCI) who have neurogenic bladder dysfunction, especially those patients who use indwelling catheters. Nationally and as reported by the federally designated Model Spinal Cord
Injury Systems, UTIs are the most common secondary medical complication of SCI during acute care or medical rehabilitation [1].

While intermittent catheterization or use of external drainage systems are widely believed to decrease the risk of symptomatic UTI and related complications in patients with SCI, these options may not be feasible for many patients because of issues secondary to medical factors, such as limited hand strength or dexterity, or because of social factors, such as catheter costs or limited insurance coverage. Unfortunately, infection control among persons with long-term indwelling catheters has not significantly advanced since the closed system of catheter drainage was introduced 3 decades ago [2]. A reported 98.5 percent of patients with SCI who have neurogenic bladders requiring management with indwelling urethral catheters develop persistent bacteriuria [3]. Efforts to prevent bacteriuria, such as bladder irrigation, instillation of antibacterial solutions in the urinary bag, rigorous meatal cleaning, and use of short-term antibiotic medications, have been shown to be ineffective [4-7].

\footnotetext{
Abbreviations: SCI = spinal cord injury, SHC = silver hydrogel catheter, UTI = urinary tract infection.

* Address all correspondence to Irene M. Estores, MD; Spinal Cord Injury Service, James A. Haley Veterans' Hospital, 13000 Bruce B. Downs Blvd, 128, Tampa, FL 33612; 813972-7517; fax: 813-978-5913. Email: irene.estores@gmail.com DOI: 10.1682/JRRD.2006.12.0154
} 
The use of systemic antibiotic prophylaxis has been widely shown to be ineffective. Morton et al.'s metaanalysis examined 15 controlled trials involving adults and adolescents with neurogenic bladder due to SCI [8]. These trials addressed antibiotic prophylaxis and used bacteriuria or UTI as an outcome. Antibiotic prophylaxis did not significantly decrease symptomatic infections, although it reduced asymptomatic bacteriuria among acute patients. The use of ascorbic acid has been shown to be ineffective, as well [9]. The efficacy of methenamine hippurate has been demonstrated in some studies but not in others. Most studies on this agent have been small, nonrandomized, and conducted on geriatric populations. One such trial found that patients receiving this drug had significantly fewer courses of antibiotic therapy for symptomatic UTI and less frequent mechanical catheter complications [10]. However, another study did not show such benefits [11]. Although studies examining the use of cranberry supplements to reduce bacteriuria in healthy subjects showed efficacy [12], two small, prospective controlled studies on the use of cranberry supplements in persons with neurogenic bladder dysfunction after SCI did not show any effect on bacteriuria, pyuria, or development of UTIs [1314]. Different types of catheters with heparin or Teflon ${ }^{\circledR}$ coatings have also been investigated but have not been clearly shown to be effective. Reduced bacterial adherence to the catheter surface with heparin was demonstrated in three different catheter types [15], but the studies did not determine whether heparin clinically reduced UTIs.

One method of UTI prevention in patients with indwelling catheters that has recently shown promise is the use of a silver hydrogel catheter (SHC). Silver is known to be antibacterial and nontoxic to mammalian tissue and has been used in various clinical settings, such as burn wounds and pressure ulcers. In the last 15 years, numerous randomized clinical trials and a meta-analysis in the general inpatient population have shown that SHCs reduce the incidence of catheter-associated nosocomial UTIs [16-20]. Prospective, randomized controlled trials involving silver alloy-coated catheters have demonstrated decreased nosocomial UTIs and the associated cost benefits in short-term inpatient settings. In fact, the Agency for Healthcare Research and Quality recently released a report (Making healthcare safer: A critical analysis of patient safety practices) listing "the use of silver alloycoated urinary catheters to prevent UTIs" as 1 of the 12 most important practices to be investigated [21].
Unfortunately, the results of these studies in acutecare inpatients cannot be generalized to patients such as those with SCI, who often require long-term indwelling catheterization. Also unknown is whether chronic use of an SHC will lead to problems related to silver toxicity. In this article, we report the case of one patient who used an SHC for 6 months and experienced no symptomatic UTIs or silver toxicity.

\section{METHODS}

The patient was a 40-year-old white male who had sixth cervical level American Spinal Injury Association tetraplegia A, had been injured for 23 years, and had been using an indwelling catheter for the same duration. He had been experiencing monthly symptomatic UTIs requiring antibiotic use in the 6 months preceding the study. He had no history of bladder stones, high-dose steroid use, or prostate or bladder surgery. He previously used a latex indwelling catheter that his caregiver changed monthly.

We defined symptomatic UTI as the presence of three of the following five conditions: (1) fever (temperature $\left.>101{ }^{\circ} \mathrm{F}\right)$, (2) bacteriuria (>100,000 organisms/mL), (3) pyuria (25-50 leukocytes $/ \mathrm{mm}^{3}$ ), (4) self-reported change in color of urine or malodorous urine, and (5) bacteremia or fungemia.

After obtaining the patient's informed consent, we tested his serum silver levels and performed urinalysis and urine cultures. The urinalysis and urine cultures were performed monthly with each catheter change, and the serum silver levels were retested at the end of the 6 months. The patient agreed to be blinded to the type of catheter he was receiving for the 6-month study period. Silver hydrogel and latex catheters look similar except for a slight difference in the color of the port. One of the authors (D.O.) changed the patient's catheter monthly. During the monthly catheter changes, the patient was also asked about symptoms suggestive of silver toxicity, such as having difficulty seeing at night, experiencing the sensation of retching or wanting to throw up daily for 3 or more days, and having no bowel movement for 1 week on his current bowel program. Clinical staff who did not know that he was using an SHC administered a questionnaire to obtain this information. 


\section{RESULTS}

During the 6 months, the patient developed no symptomatic UTIs or any symptoms suggestive of silver toxicity. His serum silver levels before and after the trial remained within normal limits (baseline $=0.9 \mathrm{ng} / \mathrm{mL}$, end of study $=1.9 \mathrm{ng} / \mathrm{mL}$ ). Although the level of bacteriuria did not change ( $>100,000$ organisms $/ \mathrm{mL}$ ), an interesting observation was that the bacterial flora had changed at the end of the trial. The patient initially had multiple drug-resistant Pseudomonas aeruginosa and enterococcus faecalis at baseline; at the end of study, the isolated organism was Escherichia coli.

\section{DISCUSSION}

The urinary bladder has numerous immune mechanisms that are compromised by an indwelling catheter. The catheter provides a conduit for microbial ascent into the bladder, partly by offering haven from the urethral epithelium, which is an effective, natural host defense. In particular, a biofilm in which glycocalyx-enclosed bacteria can thrive is known to develop on both the intraluminal and extraluminal surfaces of the catheter [22]. This biofilm can protect infectious organisms from systemic antibiotics and complicate identification of the offending microbes, because they do not readily appear on urine cultures. Another significant finding in patients with SCI and neurogenic bladder dysfunction is that uropathogens form dense biofilms on the bladder wall, which makes their eradication with conventional microbial therapy difficult [23]. Adherent biofilms provide an excellent habitat for bacteria, allowing them to exchange genetic information that encode for drug resistance.

The presence of a neurogenic bladder dysfunction after SCI further compromises the mechanisms that prevent UTIs. In addition to increased instrumentation, several structural and physiological factors, such as bladder overdistension, vesicoureteral reflux, and high-pressure voiding, increase the risk of UTIs in patients with SCI. The kidney is not protected by mechanisms that decrease bacterial adherence, and some bacterial species can gain access to the kidneys in the presence of reflux, leading to serious complications [24]. Mucosal ischemia associated with obstructed high-pressure voiding or poor bladderwall compliance may also facilitate tissue invasion [25]. Residual urine forms a nutritional substrate that supports bacterial growth. From an initial colonization stage, which gives rise initially to asymptomatic bacteriuria, these bacteria at a certain point can cause tissue invasion and subsequent infection. In this single subject, using the SHC for 6 months did not affect his level of bacteriuria but prevented the development of symptomatic UTIs.

Silver has long been used as an antimicrobial agent and in the treatment of burns and pressure ulcers. Silver ions have a broad-spectrum activity against gram-positive, gram-negative, aerobic, and anaerobic microorganisms [26]. It is also virucidal against a variety of viral agents, for example, poliovirus, adenovirus, bovine virus, rotavirus, herpes, and vaccinia virus [27]. The activity of silver against multiresistant strains, including methicillin sodium-resistant staphylococci and vancomycin-resistant enterococci is particularly important. This action is postulated to be mediated by binding of the silver ions to cellular DNA [28] and the cell membrane [29]. Resistance to silver has been reported in a small number of organisms, including some strains of Proteus mirabilis, Enterobacter cloacae, Citrobacter freundii, and Klebsiella pneumoniae [30].

In light of this information about silver, Akiyama and Okamoto first developed a silver-coated catheter in 1979 [31]. Subsequent studies showed a decreased adherence of microbes to this silver-coated catheter surface, particularly gram-positive organisms and yeast from the periurethral flora. The in vitro antiadherence of silver alloycoated hydrogel catheters is also superior to silicone or hydrogel-coated catheters [32]. Reduced adherence of these bacteria has been demonstrated in silver-alloy catheters at 2 and 18 hours, as indicated by radiolabeled cell assays with the use of a silver coating. Pseudomonas aeruginosa cells have been shown to not grow or adhere to silver-coated catheter latex [33].

Silver is ingested with food in a concentration of 1 to $88 \mu \mathrm{g} /$ day. The accepted silver limits for drinking water in the United States is $50 \mu \mathrm{g} / \mathrm{L}$. Only 10 percent of the ingested amount is absorbed into the intestine and 90 percent passes out with the stool. Argyria is a condition that occurs when silver is deposited in the body; it can be a local or systemic problem. When a mucous membrane is exposed to silver, argyria can cause the person to manifest systemic symptoms such as nausea, constipation, and loss of night vision [34]. The visual abnormality is due to silver deposition in the Descemet membrane. Silver has a good safety profile, but most published data relate to its short-term use. Patients with extensive burns who receive local treatment with preparations containing silver have 
been shown to have serum concentrations of up to $60 \mu \mathrm{g} / \mathrm{dL}$ and urine concentrations of $1,100 \mu \mathrm{g}$ in 24 hours without developing clinical consequences or signs of argyria [35]. However, in a previous clinical trial [36], 10 percent of men reported a black discharge and irritation from the study's silver-coated catheter; these results were not noted in the control group. After using the SHC for 6 months, our patient did not develop any signs of silver toxicity or experience elevated serum silver levels outside the normal range.

\section{CONCLUSIONS AND RECOMMENDATIONS}

For this single patient, the use of an indwelling SHC effectively prevented the development of symptomatic UTIs for 6 months. He did not display any symptoms suggestive of silver toxicity or increased serum levels of silver with this chronic use of the device. Since no previous study has reported the safe use of an SHC outside acute settings, this observation is also of prime importance. Although, clearly, no general conclusions can be drawn from this single-subject observation, the results demonstrate that the device was safe and effective for this patient and that further study must determine its safety and efficacy for persons with SCI requiring indwelling catheterization for bladder management. If the efficacy and safety of this device's long-term use are supported by the results of a large trial, a change in clinical practice and subsequent improvement of patient care may occur.

\section{ACKNOWLEDGMENTS}

We wish to thank Howard Choi, MD, MPH; Marca Sipski Alexander, MD; Chester Ho, MBBChr; and Diana Cardenas, MD, MHA.

This material was based on work supported by the Department of Veterans Affairs Rehabilitation Research and Development Service (grant 53045C). exist.

The authors have declared that no competing interests

\section{REFERENCES}

1. Cardenas DD, Hooton TM. Urinary tract infection in persons with spinal cord injury. Arch Phys Med Rehabil. 1995; 76(3):272-80. [PMID: 7717822]
2. Kunin CM, McCormack RC. Prevention of catheterinduced urinary-tract infections by sterile closed drainage. New Engl J Med. 1966;274(21):1155-61.

[PMID: 5934951]

3. Newman E, Price M. Bacteriuria in patients with spinal cord lesions: Its relationship to urinary drainage appliances. Arch Phys Med Rehabil. 1977;58(10):427-30. [PMID: 907447]

4. Huth TS, Burke JP, Larsen RA, Classen DC, Stevens LE. Randomized trial of meatal care with silver sulfadiazine cream for the prevention of catheter-associated bacteriuria. J Infect Dis. 1992;165(1):14-18. [PMID: 1727882]

5. Warren JW, Platt R, Thomas RJ, Rosner B, Kass EH. Antibiotic irrigation and catheter-associated urinary-tract infections. N Engl J Med. 1978;299(11):570-73. [PMID: 210379]

6. Thompson RL, Haley CE, Searcy MA, Guenthner SM, Kaiser DL, Gröschel DH, Gillenwater JY, Wenzel RP. Catheter-associated bacteriuria. Failure to reduce attack rates using periodic instillations of a disinfectant into urinary drainage systems. JAMA. 1984;251(6):747-51. [PMID: 6363727]

7. Stover SL, Lloyd LK, Waites KB, Jackson AB. Urinary tract infection in spinal cord injury. Arch Phys Med Rehabil. 1989;70(1):47-54. [PMID: 2644914$]$

8. Morton SC, Shekelle PG, Adams JL, Bennett C, Dobkin BH, Montgomerie J, Vickrey BG. Antimicrobial prophylaxis for urinary tract infection in persons with spinal cord dysfunction. Arch Phys Med Rehabil. 2002;83(1):129-38. [PMID: 11782843]

9. Castelló T, Girona L, Gómez MR, Mena Mur A, García L. The possible value of ascorbic acid as a prophylactic agent for urinary tract infection. Spinal Cord. 1996;34(10):592-93. [PMID: 8896124$]$

10. Nyrén P, Runeberg L, Kostiala AI, Renkonen OV, Roine R. Prophylactic methenamine hippurate or nitrofurantoin in patients with an indwelling urinary catheter. Ann Clin Res. 1981;13(1):16-21. [PMID: 7247321]

11. Vainrub B, Musher DM. Lack of effect of methenamine in suppression of, or prophylaxis against, chronic urinary infection. Antimicrob Agents Chemother. 1977;12(5):625-29. [PMID: 921259]

12. Di Martino P, Agniel R, David K, Templer C, Gaillard JL, Denys P, Botto H. Reduction of Escherichia coli adherence to uroepithelial bladder cells after consumption of cranberry juice: A double-blind randomized placebo-controlled cross-over trial. World J Urol. 2006;24(1):21-27. [PMID: $\underline{163978141}$

13. Waites KB, Canupp KC, Armstrong S, DeVivo MJ. Effect of cranberry extract on bacteriuria and pyuria in persons with neurogenic bladder secondary to spinal cord injury. J Spinal Cord Med. 2004;27(1):35-40. [PMID: 15156935] 
14. Linsenmeyer TA, Harrison B, Oakley A, Kirshblum S, Stock JA, Millis SR. Evaluation of cranberry supplement for reduction of urinary tract infections in individuals with neurogenic bladders secondary to spinal cord injury: A prospective, double-blinded, placebo-controlled, crossover study. J Spinal Cord Med. 2004;27(1):29-34. [PMID: 15156934$]$

15. Ruggieri MR, Hanno PM, Levin RM. Reduction of bacterial adherence to catheter surface with heparin. J Urol. 1987; 138(2):423-26. [PMID: 3298698]

16. Saint S, Elmore JG, Sullivan SD, Emerson SS, Koepsell TD. The efficacy of silver alloy-coated urinary catheters in preventing urinary tract infection: A meta-analysis. Am J Med. 1998;105(3):236-41. [PMID: 9753027]

17. Thibon P, Le Coutour X, Leroyer R, Fabry J. Randomized multi-centre trial of the effects of a catheter coated with hydrogel and silver salts on the incidence of hospitalacquired urinary tract infections. J Hosp Infect. 2000;45(2): 117-24. [PMID: 10860688]

18. Liedberg H, Lundeberg T. Silver alloy coated catheters reduce catheter-associated bacteriuria. Br J Urol. 1990;65(4): 379-81. [PMID: 2187551]

19. Bologna RA, Tu LM, Polansky M, Fraimow HD, Gordon DA, Whitmore KE. Hydrogel/silver ion-coated urinary catheter reduces nosocomial urinary tract infection rates in intensive care unit patients: A multicenter study. Urology. 1999;54(6):982-87. [PMID: 10604694$]$

20. Karchmer TB, Giannetta ET, Muto CA, Strain BA, Farr BM. A randomized crossover study of silver-coated urinary catheters in hospitalized patients. Arch Intern Med. 2000; 160(21):3294-98. [PMID: 11088092]

21. Shojania KG, Duncan BW, McDonald KM, Wachter RM, Markowitz AJ. Making health care safer: A critical analysis of patient safety practices. Evid Rep Technol Assess (Summ). 2001;(43):i-x,1-668. [PMID: 11510252]

22. Nickel JC, Downey JA, Costerton JW. Ultrastructural study of microbiologic colonization of urinary catheters. Urology. 1989;34(5):284-91. [PMID: 2815452]

23. Reid G, Charbonneau-Smith R, Lam D, Yang YS, Lacerte $\mathrm{M}$, Hayes KC. Bacterial biofilm formation in the urinary bladder of spinal cord injured patients. Paraplegia. 1992; 30(10):711-17. [PMID: 1448299]

24. Kuhlemeier KV, Lloyd LK, Stover SL. Failure of antibodycoated bacteria and bladder washout tests to localize infection in spinal cord injury patients. J Urol. 1983;130(4): 729-32. [PMID: 6350622]
25. Lloyd-Davies RW, Hinman F Jr. Structural and functional changes leading to impaired bacterial elimination after overdistension of the rabbit bladder. Invest Urol. 1971;9(2): 136-42. [PMID: 4941110]

26. Guggenbichler JP, Böswald M, Lugauer S, Krall T. A new technology of microdispersed silver in polyurethane induces antimicrobial activity in central venous catheters. Infection. 1999;27 Suppl 1:S16-23. [PMID: 10379438]

27. Moroz OG, Kulskii LA, Prokuryanova NB, Rudenko AV, Florensova KM. Susceptibility of organisms which cause intestinal infections to removal by silver. Khm Technol. 1980; 2:275-81.

28. Favre A, Michelson AM, Yaniv M. Photochemistry of 4-thiouridine in Escherichia coli transfer RNA1Val. J Mol Biol. 1971;58(1):367-79. [PMID: 4932656]

29. Rosenkranz HS, Carr HS. Silver sulfadiazine: Effect on the growth and metabolism of bacteria. Antimicrob Agents Chemother. 1972;2(5):367-72. [PMID: 4597116]

30. Hendry AT, Stewart IO. Silver-resistant Enterobacteriaceae from hospital patients. Can J Microbiol. 1979;25(8):915-21. [PMID: 526888$]$

31. Akiyama H, Okamoto S. Prophylaxis of indwelling urethral catheter infection: Clinical experience with a modified Foley catheter and drainage system. J Urol. 1979; 121(1):40-42. [PMID: 759642]

32. Gabriel MM, Sawant AD, Simmons RB, Ahearn DG. Effects of silver on adherence of bacteria to urinary catheters: In vitro studies. Curr Microbiol. 1995;30(1):17-22. [PMID: 7765878$]$

33. Liedberg H, Lundeberg T, Ekman P. Refinements in the coating of urethral catheters reduces the incidence of catheter-associated bacteriuria. An experimental and clinical study. Eur Urol. 1990;17(3):236-40. [PMID: 2190840]

34. Rosenblatt MJ, Cymet TC. Argyria: Report of a case associated with abnormal electroencephalographic and brain scan findings. J Am Osteopath Assoc. 1987;87(7):509-12. [PMID: 3112046]

35. Boosalis MG, McCall JT, Ahrenholz DH, Solem LD, McClain CJ. Serum and urinary silver levels in thermal injury patients. Surgery. 1987;101(1):40-43. [PMID: 3798326]

36. Riley DK, Classen DC, Stevens LE, Burke JP. A large randomized clinical trial of a silver-impregnated urinary catheter: lack of efficacy and staphylococcal superinfection. Am J Med. 1995;98(4):349-56. [PMID: 7709947]

Submitted for publication December 6, 2006. Accepted in revised form August 2, 2007. 